\title{
Patient safety culture assessment in Iran using the "Hospital survey on patient safety culture" tool: A systematic review and meta-analysis
}

\author{
Masoud Behzadifar ${ }^{\mathrm{a}, *}$, Meysam Behzadifar ${ }^{\mathrm{b}}$, Firuzeh Jahanpanah ${ }^{\mathrm{c}}$, Nicola Luigi Bragazzi ${ }^{\mathrm{d}}$ \\ ${ }^{a}$ Department of Public Health, Faculty of Health and Nutrition, Lorestan University of Medical Sciences, Khorramabad, Iran \\ ${ }^{\mathrm{b}}$ Health Management and Economics Research Center, Iran University of Medical Sciences, Tehran, Iran \\ ' Social Determinants of Health Research Center, Lorestan University of Medical Sciences, Khorramabad, Iran \\ ${ }^{\mathrm{d}}$ School of Public Health, Department of Health Sciences (DISSAL), University of Genoa, Genoa, Italy
}

\section{A R T I C L E I N F O}

\section{Keywords:}

Patient safety culture

Iran

Hospital survey on patient safety culture

Systematic review

Meta-analysis

\begin{abstract}
A B S T R A C T
Background: Paying attention to patient safety is a crucial aspect of the healthcare provision delivery. Integrating and coordinating the different parts of the health system can ensure a safe, high-quality and efficient care. Patient safety culture (PSC) is a broad, complex and multi-dimensional conceptual framework. In recent years, several studies have been conducted to evaluate PSC using the "Hospital Survey on Patient Safety Culture" (HSOPSC) tool. The aim of this study was to examine the level of PSC in Iranian hospitals.

Methods: ISI/Web of Sciences (WoS), PubMed/MEDLINE, Embase, CINAHL, PsychINFO and Scopus as well as Iranian databases including MagIran and SID were searched from January 2000 to July 2018. The NewcastleOttawa Scale checklist was used to assess the quality of the studies. The mean score of the participants' responses for each dimension of the questionnaire was calculated using the DerSimonian-Laird's random model with a $95 \%$ confidence interval.

Results: In the current systematic review and meta-analysis, 27 studies conducted between 2012 and 2017 were included. The participants were 9264. Low scores (in the range 37.79-65.43) were found, especially when compared to other countries such as Lebanon, Turkey and the USA.

Conclusion: Our results showed that in Iran the level of PSC is low and requires special attention from healthcare managers and providers. PSC should be a very important priority in Iran's health sector. Health decision- and policy-makers should pay particular attention to offering training programs to promote and develop PSC.
\end{abstract}

\section{Background}

Paying attention to patient safety is a crucial aspect of the healthcare provision delivery. Nowadays, in advanced countries, measuring this indicator is of high interest for the healthcare providers to make evidence-based decision and implement adequate plans and programs. ${ }^{1}$ Properly integrating and coordinating the different parts of the health system can ensure a safe, efficient and high-quality healthcare. ${ }^{2}$ Patient safety culture (PSC) is a broad, complex and multi-dimensional conceptual framework, ${ }^{3}$ which enables to assess the behavior of individuals and organizations based on shared beliefs and values. The ultimate goal of PSC is to reduce injuries and increase patient safety. ${ }^{4}$ In presence of high safety standards, errors are less likely to occur, and, when they occur, are promptly reported. ${ }^{5,6}$

Deaths due to unwanted but avoidable accidents have led hospital managers to consider PSC as their top priority. ${ }^{7,8}$ Different healthcare organizations, including hospitals and other healthcare centers, are working to provide an appropriate assessment of PSC in order to improve patient safety-related procedures. ${ }^{9}$ Unfortunately, despite the relevant damage caused by insecure care, there is little evidence of the role and effect of PSC in developing countries, and therefore, these countries do not have a good understanding of the patient's safety status in their hospitals. ${ }^{10,11}$

The "Hospital Survey on Patient Safety Culture" (HSOPSC) developed by the Agency for Healthcare Research and Quality (AHRQ) can be used to assess PSC. ${ }^{12}$ HSOPSC is a validated, reliable tool, which comprises of 12 dimensions and 42 questions. It is psychometrically sound, and confirmed by extensive analyses including item analysis, reliability assessment, inter-correlation, exploratory and confirmatory factor analysis. ${ }^{13-15}$ This tool has been translated into different languages and is used in several countries. It can help healthcare managers, policy- and decision-makers design ad hoc interventions and

\footnotetext{
* Corresponding author.

E-mail addresses: masoudbehzadifar@gmail.com, behzadifar@lums.ac.ir (M. Behzadifar).
} 


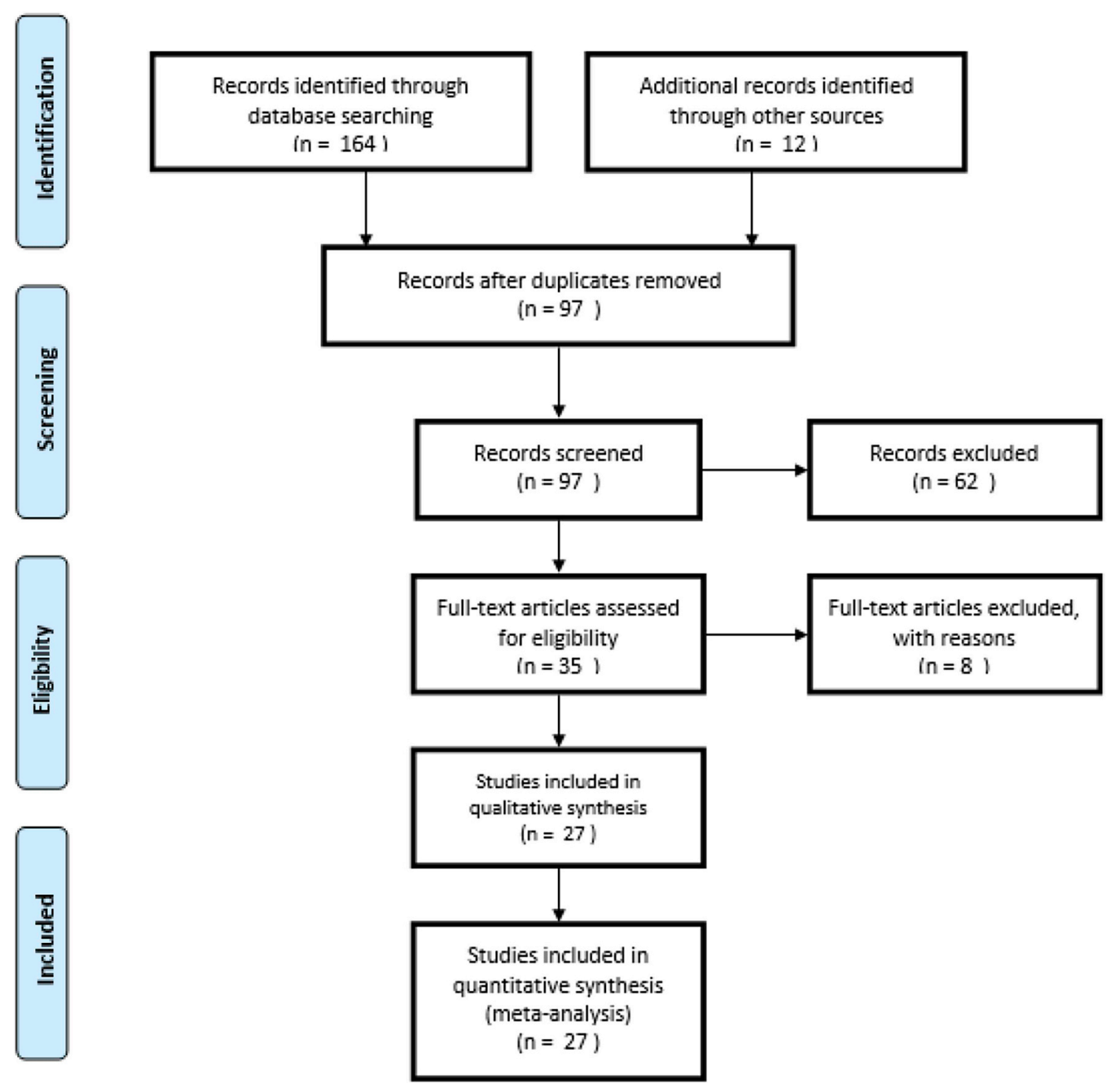

Fig. 1. Selection process workflow.

measures.

Iran is one of the developing countries that offers widespread hospital services, whose safety levels and standards need to be monitored by healthcare decision- and policy-makers, in order to improve and enhance the level of PSC in the country. In recent years, several studies have been conducted to evaluate PSC utilizing the HSOPSC tool. The aim of this study was to examine the level of PSC in Iranian hospitals through a systematic review and meta-analysis of the published investigations.

\section{Methods}

\subsection{Search strategy}

The present study was based on the "Preferred Reporting Items for Systematic Reviews and Meta-Analyses" (PRISMA) guidelines, ${ }^{16}$ reported in Appendix 1. International scholarly databases such as ISI/ Web of Sciences (WoS), PubMed/MEDLINE, Embase, CINAHL, PsychINFO and Scopus as well as Iranian databases including MagIran and SID were searched from January 2000 to July 2018. The following search strategy was used: ("Patients safety culture" OR "Patient culture" OR "PSC" OR "Patient safety" OR "Safety" OR "Hospital safety" OR "Safety climate" OR "Hospital survey") AND ("Hospital" OR
"Government hospital" OR "Private hospital" OR "Teaching hospital") AND ("Hospital Survey on Patient Safety Culture" OR "HSOPSC") AND ("Iran"). Also, each reference list of the included studies was handsearched for getting more relevant studies and reducing the risk of missing potentially eligible investigations.

\subsection{Inclusion and exclusion criteria}

We included studies that: i) used the HSOPSC tool for PSC evaluation, ii) were published either in Persian or English, and iii) were conducted in hospitals. We excluded studies that: i) used a tool other than HSOPSC, ii) were carried out outside of hospitals and healthcare centers and iii) did not fully report the 12 dimensions of the instrument.

\subsection{Data extraction}

Two authors independently extracted relevant study data and information, including the surname of the first author, the year of publication, the city of the study, the number and type of participants, and the scores for the items in the questionnaire. Disagreements between the two authors were resolved through discussion. 


\subsection{Quality assessment}

The Newcastle-Ottawa Scale (NOS) checklist was used to critically appraise the quality of the retained studies. This checklist assesses 3 domains (namely, selection, comparability and outcomes). Evaluation of the quality of studies is reported in Appendix 2.

\subsection{Data analysis}

The mean score of the participants' responses for each dimension of the questionnaire was calculated using the DerSimonian-Laird's random model with a $95 \%$ confidence interval (CI). ${ }^{17}$ To evaluate heterogeneity among included studies, $\mathrm{I}^{2}$ test was used. ${ }^{18}$ Egger's linear regression test was used to evaluate the publication bias. ${ }^{19}$ Sensitivity analysis was also performed to ensure the stability of the results for all the dimensions of the questionnaire. ${ }^{20}$ All statistical significances were set at pvalues less than 0.05 . All data were analyzed using the commercial software STATA Ver.14 (Stata Corp, College Station, TX, USA).

\section{Results}

The process of searching and selecting proper studies is pictorially represented in Fig. 1. In the initial search, 176 studies were found and, after the removal of duplicates, 97 of them were retained. At this stage, 35 studies were selected based on title and/or abstract review and the removal of irrelevant studies. The full text of these 35 studies was reviewed in depth and, in the end, 27 studies were deemed eligible for inclusion in the present systematic review and meta-analysis. ${ }^{21-47}$

Studies were conducted between 2012 and 2017. Participants were 9264. The main characteristics of the selected studies are shown in Table 1.

The mean of the responses of the 12 dimensions of the HSPSC tool is given in Table 2 and Appendix 3. More in detail, higher scores were reported for the dimension of "organizational learning and continuous improvement" (mean 65.43), whereas lower scores for the dimension of "non-punitive response to error" (mean 37.79).

Sensitivity-analysis was performed. Before and after the sensitivity

Table 1

Characteristics of studies.

\begin{tabular}{|c|c|c|c|c|}
\hline Name & Year & Participants & City & Sample size \\
\hline Abdi & 2012 & Mixed & Tehran & 311 \\
\hline Boghaei & 2012 & Mixed & Uromia & 500 \\
\hline Ravaghi & 2012 & Mixed & Tehran & 216 \\
\hline Ebadi fard azar & 2012 & Mixed & Tehran & 145 \\
\hline Agharahimi & 2012 & Mixed & Isfahan & 94 \\
\hline Moghri & 2012 & Mixed & Tehran & 343 \\
\hline Yaghobi Far & 2012 & Mixed & Sabzevar & 207 \\
\hline Adibi & 2012 & Mixed & Tehran & 90 \\
\hline Arabloo & 2012 & Mixed & Qazvin & 145 \\
\hline Moussavi & 2013 & Mixed & Tehran & 175 \\
\hline Davoodi & 2013 & Mixed & Mashhad & 922 \\
\hline Izadi & 2013 & Mixed & Isfahan & 196 \\
\hline Moghri & 2013 & Mixed & Several city & 725 \\
\hline Bahrami & 2014 & Nurses & Yazd & 340 \\
\hline Momeni & 2014 & Mixed & Tehran & 332 \\
\hline Hemmat & 2015 & Nurses & Isfahan & 83 \\
\hline Faghihzadeh & 2015 & Nurses & Amol & 530 \\
\hline Mohebi Far & 2015 & Mixed & Tehran & 312 \\
\hline Saber & 2015 & Mixed & Kerman & 439 \\
\hline Arshadi Bostanabad & 2015 & Nurses & Tabriz & 99 \\
\hline Almasi & 2015 & Mixed & Kermanshah & 872 \\
\hline Rezaean & 2016 & Mixed & Yasuj & 361 \\
\hline Asefzadeh & 2017 & Nurses & Sari & 380 \\
\hline Ghahramanian & 2017 & Nurses-Physician & Tabriz & 401 \\
\hline Akbari & 2017 & Mixed & Ilam & 299 \\
\hline Farzi & 2017 & Nurses & Isfahan & 367 \\
\hline Kabodi & 2017 & Mixed & Kermanshah & 380 \\
\hline
\end{tabular}

Mixed: Physicians-nurses-other staff. analysis, results did not change and confirmed the stability of the findings. Publication bias assessment was also performed by the Egger's linear regression test, and results showed that there was no evidence of publication bias. The results of the 12 dimensions of this tool in Iran, compared to other countries such as the USA, ${ }^{48}$ Lebanon, ${ }^{49}$ Ethiopia ${ }^{50}$ and Turkey, ${ }^{51}$ are presented in Fig. 2 . The mean of reporting events in the included studies is shown in Table 3 . The results of mean of reporting events in Iran, compared to other countries like the USA, ${ }^{48}$ Lebanon, ${ }^{49}$ and Ethiopia, ${ }^{50}$ are presented in Fig. 3. The mean of graded responses is reported in Table 4. These results compared to other countries like the USA, ${ }^{48}$ Lebanon, $^{49}$ Ethiopia $^{50}$ and Turkey ${ }^{51}$ are shown in Fig. 4.

\section{Discussion}

One of the challenges faced by the healthcare sectors and systems in both developed and developing countries is to increase the level of PSC. Health service providers are trying to create a good environment for the staff in order to make them properly understand and apply this crucial concept. ${ }^{52}$ Assessing the status of PSC helps the organization become aware of the different aspects of patient safety that require serious attention. It also enables hospitals and healthcare providers to identify the strengths and weaknesses of their organizational culture in terms of patient safety and existing problems in this area. ${ }^{49}$ Health policy- and decision-makers in Iran should work to create a just and proper culture in the workplace and encourage healthcare workers to report incidents, events and mistakes. Health policy- and decision-makers need to consider PSC as a serious concern and to try to correct the culture of blame and punishment. They should encourage organizations to continually improve PSC-related processes and procedures.

Our results showed that the means of the responses for the different dimensions of the questionnaire ranged from 37.79 to 65.43 . The dimension's scores measured in this study are low compared to the results of studies conducted in other countries, such as the USA, Lebanon and Turkey, which emphasizes that the concepts of PSC are unknown to many Iranian hospitals' staff members and managers.

Our findings concerning mean scores of the non-punitive response to error dimension are consistent with Al Ahmadi's study in Saudi Arabia, ${ }^{53}$ Chen's study in Taiwan ${ }^{54}$ and Al-Mandhari's study in Oman. ${ }^{55}$ Non-punitive response to error is a very important factor that enables errors to be early detected and reported, contributing to their decreasing trend. ${ }^{56}$ Many Iranian staff members in hospitals tend to under-report errors, being afraid of the consequences and being worried about punitive policies. ${ }^{57}$ In many Iranian health service centers, punishing workers who commit mistakes is considered the easiest option by managers and providers, without paying attention to the root causes of errors. It seems to be a major challenge in organizations such as hospitals to promote a continuous learning and promotion environment. A systematic approach in dealing with errors in organizations can create a positive safety culture that discourages managers from taking punitive action. ${ }^{58}$ For this reason, the American health association has recommended that organizations should reject punitive culture, putting aside mistakes caused by personnel and individual failures, and transforming mistakes in learning opportunities.

The highest level of accountability in this study regards the organizational learning and continuous improvement dimension, which is consistent with the studies done in Saudi Arabia, ${ }^{53}$ Lebanon $^{49}$ and Oman. ${ }^{55}$

Improving PSC requires the development of adequate training programs focused on the concepts of PSC to instruct all the staff members of an organization. Furthermore, this process should be performed on a regular basis, in order to be properly monitored and improved. Organizations that provide ongoing training on this issue for their employees are, indeed, successful and with a very low rate of errors and mistakes. Accreditation and clinical governance policy can play a positive role in promoting PSC. ${ }^{59}$ In recent years, health managers, 
Table 2

Mean of 12 dimensions of HSOPSC tool in Iran.

\begin{tabular}{|c|c|c|c|}
\hline Items & Mean of positive responses on patient safety culture dimensions (\%) $95 \% \mathrm{CI}$ & $\mathrm{I}^{2}$ & $\mathrm{P}$ value \\
\hline Organizational learning and continuous improvement & $65.43(58.62-72.24)$ & $100 \%$ & 0.000 \\
\hline Manager expectations and actions promoting safety & $60.76(55.70-65.81)$ & $100 \%$ & 0.000 \\
\hline Teamwork within units & $60.50(64.66-74.34)$ & $100 \%$ & 0.000 \\
\hline Overall perceptions of patient safety & $58.8(52.46-63.69)$ & $100 \%$ & 0.000 \\
\hline Feedback and communication about error & $55.10(49.47-60.73)$ & $100 \%$ & 0.000 \\
\hline Management support for patient safety & $52.71(46.37-59.05)$ & $100 \%$ & 0.000 \\
\hline Hospital handoffs and transitions & $51.62(44.95-58.29)$ & $100 \%$ & 0.000 \\
\hline Teamwork across hospital units & $50.28(44.82-55.75)$ & $100 \%$ & 0.000 \\
\hline Frequency of events reported & $49.53(43.12-55.95)$ & $100 \%$ & 0.000 \\
\hline Communication openness & $49.25(43.97-54.52)$ & $100 \%$ & 0.000 \\
\hline Staffing & $41.25(33.70-48.80)$ & $100 \%$ & 0.000 \\
\hline Non-punitive response to error & $37.79(30.05-45.53)$ & $100 \%$ & 0.000 \\
\hline
\end{tabular}

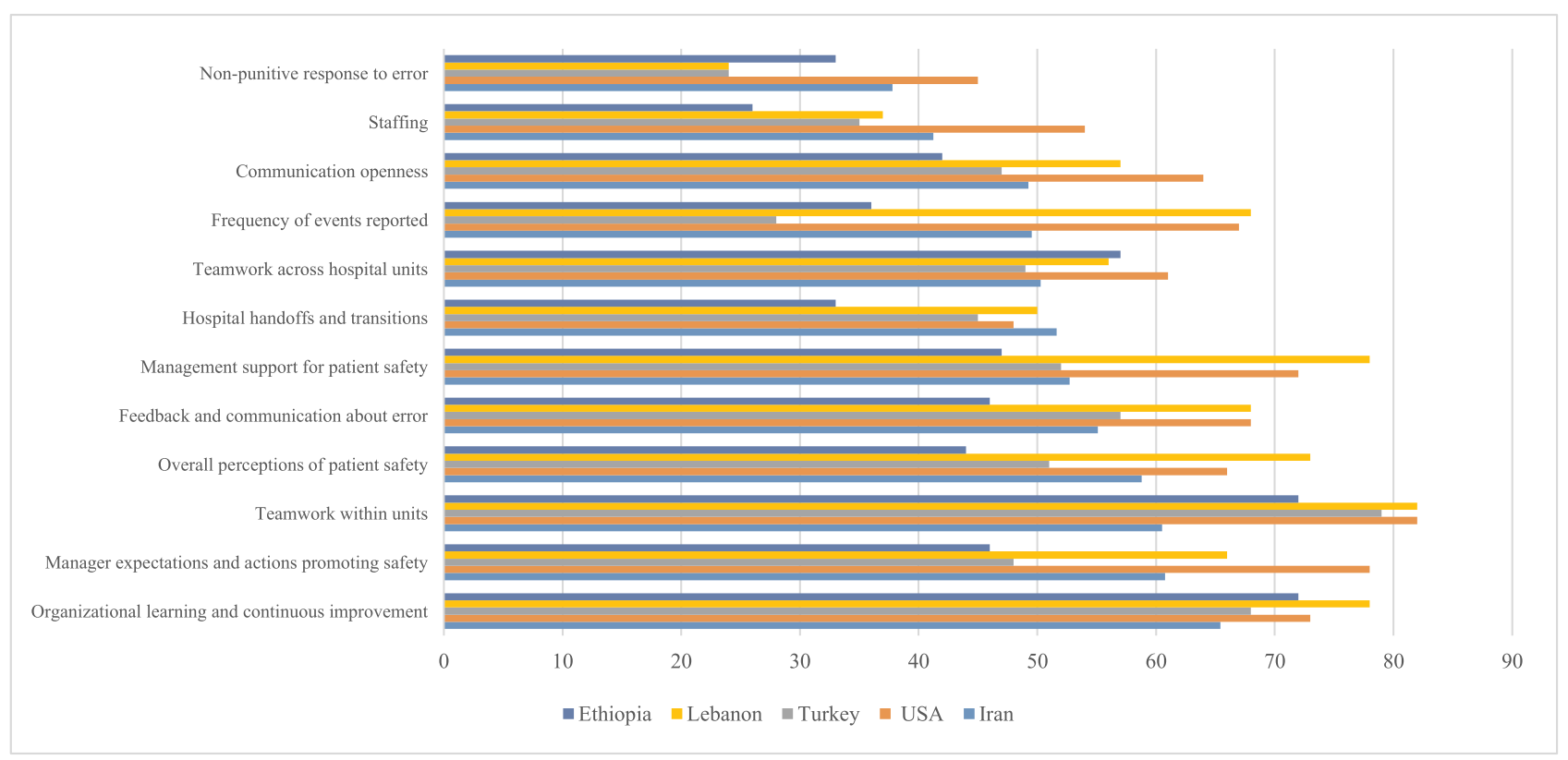

Fig. 2. Comparison of mean response in Iran versus other countries.

Table 3

Mean of reporting events of HSOPSC tool in Iran.

\begin{tabular}{llll}
\hline Number of reporting events & Mean (\%) 95\% CI & $\mathrm{I}^{2}$ & P value \\
\hline $1-2$ & $28.59(22.67-34.50)$ & $100 \%$ & 0.000 \\
$3-5$ & $9.73(7.63-11.82)$ & $100 \%$ & 0.000 \\
$6-10$ & $3.76(3.07-4.45)$ & $100 \%$ & 0.000 \\
$11-20$ & $1(0.48-1.52)$ & $100 \%$ & 0.000 \\
$>20$ & $1.20(0.22-2.18)$ & $100 \%$ & 0.000 \\
No event & $54.19(45.56-62.81)$ & $100 \%$ & 0.000 \\
\hline
\end{tabular}

decision- and policy-makers in Iran have begun to pay special attention to hospital accreditation, and this has had a very positive impact on PSC, ${ }^{60}$ even though there is room for further improvement and standards are still not completely satisfactory.

Regarding the error reporting, our study results show that compared to other countries the staff members of Iranian hospitals tend to underreport errors. A qualitative study has shown that fear of being punished by managers, high workload, being subjected to personal accountability, and misuse of the report, are among the main determinants for this under-reporting. ${ }^{61}$

In this regard, the staff members' trust and confidence towards healthcare managers and providers, and the assurance of a proper and not punitive treatment can lead to an early discovering and reporting of errors, ultimately making efforts to find and mitigate/counteract their causes and consequences.

Despite its methodological rigor, this study suffers from some limitations, which include: a) the high observed heterogeneity, which can be due to methodological differences among selected studies; b) the lack of data concerning many hospitals in Iranian provinces, which have not performed so far any safety assessment of PSC; and c) the dearth of information concerning groups different from nurses, such as hospital managers, physicians and specialists, which has made it impossible to specifically assess PSC among different groups.

\section{Conclusion}

The present study was conducted to investigate the status of PSC in Iranian hospitals. Results showed that the level of PSC is low and requires special attention from healthcare managers and providers. PSC should be a very important priority for Iran's health sector. Health decision-and policy-makers should pay particular attention to offering training programs in order to promote adequate levels of PSC in the country.

\section{Declarations}

\section{Authors' contributions}

Study design: $\mathrm{MB}, \mathrm{MeB}$, Collected data: $\mathrm{MB}, \mathrm{FJ}$ and $\mathrm{MeB}$, Data 


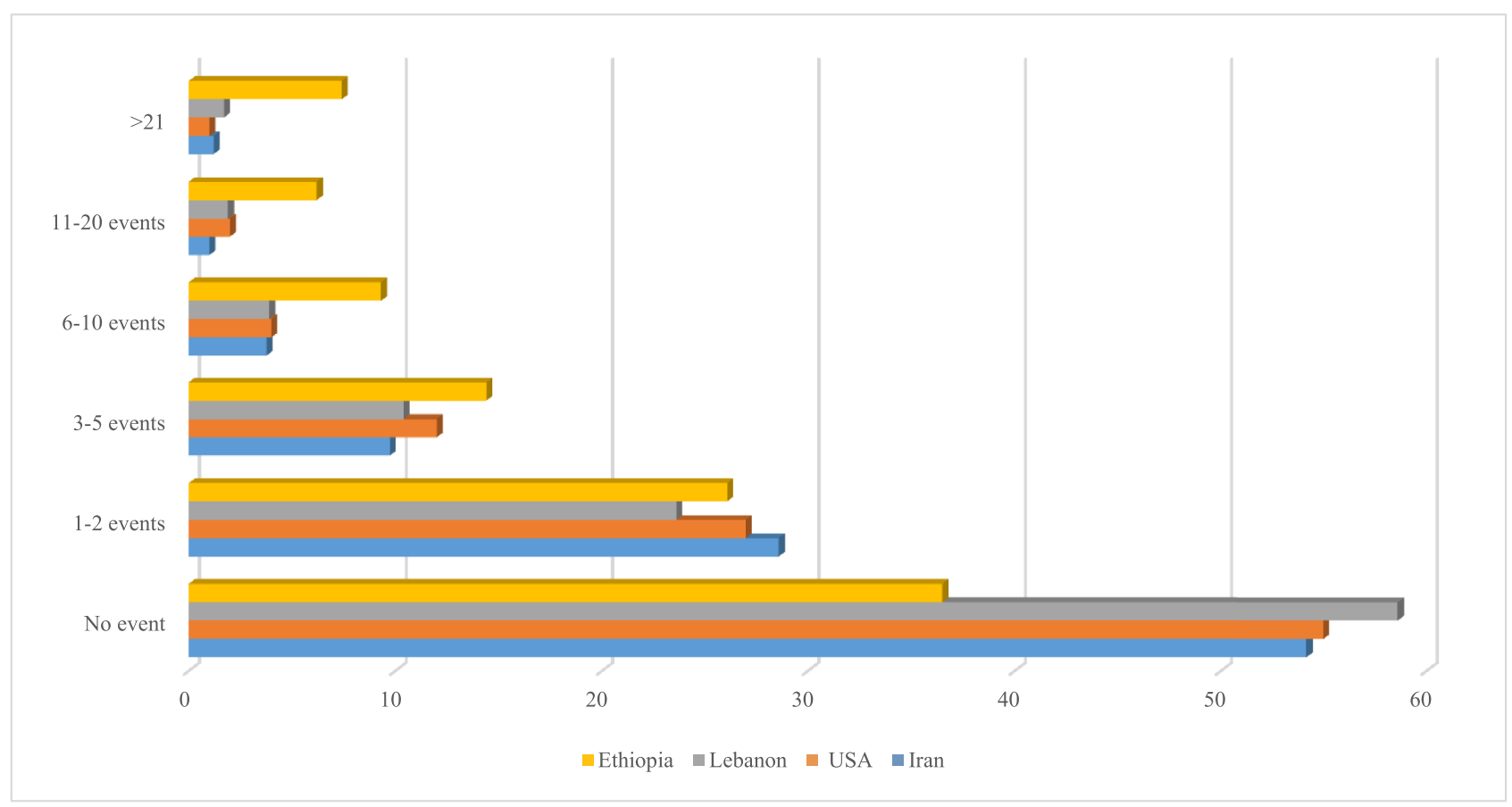

Fig. 3. Comparison of mean of reporting events in Iran versus other countries.

Table 4

Mean of graded responses as assessed by means of HSOPSC tool in Iran.

\begin{tabular}{llll}
\hline Items & Mean (\%) 95\% CI & $\mathrm{I}^{2}$ & P value \\
\hline Excellent & $4.74(2.88-6.61)$ & $100 \%$ & 0.000 \\
Very good & $19.70(14.40-25)$ & $100 \%$ & 0.000 \\
Acceptable & $55.93(51.20-60.66)$ & $100 \%$ & 0.000 \\
Poor & $12.48(8.05-16.9)$ & $100 \%$ & 0.000 \\
Failing & $6.51(2.44-10.57)$ & $100 \%$ & 0.000 \\
\hline
\end{tabular}

analysis: $\mathrm{MB}, \mathrm{MeB}$, Final revision and grammar editing: NLB, MB, and Me. All authors read and approved the final manuscript.

\section{Funding \\ Not applicable. \\ Conflict of interest}

The authors declare that they have no competing interests.

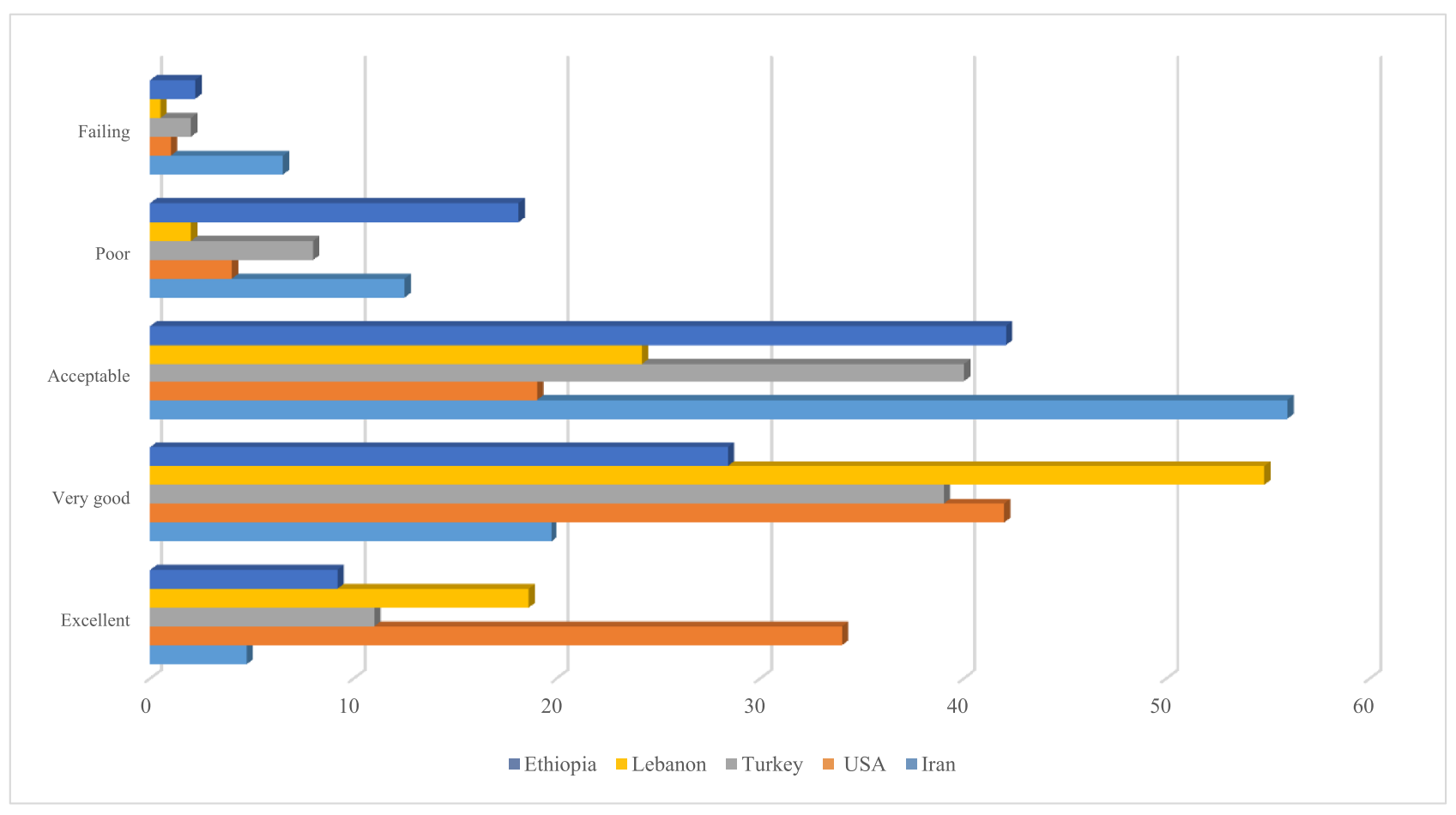

Fig. 4. Comparison of mean PSC grade of Iran with other countries. 


\section{Ethics approval}

Not applicable.

\section{Acknowledgements}

Not applicable.

\section{Abbreviations \\ PSC Patient safety culture \\ HSOPSC Hospital Survey on Patient Safety Culture \\ AHRQ Agency for Healthcare Research and Quality \\ PRISMA Preferred Reporting Items for Systematic Reviews and Meta- Analyses \\ CI Confidence interval}

\section{Appendix A. Supplementary data}

Supplementary data to this article can be found online at https:// doi.org/10.1016/j.cegh.2019.02.008.

\section{References}

1. Nie Y, Mao X, Cui H, He S, Li J, Zhang M. Hospital survey on patient safety culture in China. BMC Health Serv Res. 2013;13:228.

2. Hughes RG, Clancy CM. Working conditions that support patient safety. J Nurs Care Qual. 2005;20:289-292.

3. Sexton JB, Helmreich RL, Neilands TB, et al. The safety attitudes questionnaire: psychometric properties, benchmarking data, and emerging research. BMC Health Serv Res. 2006;6:44

4. Ronald GS. Developing and operationalizing a culture of safety. Chinese Hosp. 2005;9:7-8.

5. Zohar D. A group-level model of safety climate: testing the effect of group climate on microaccidents in manufacturing jobs. J Appl Psychol. 2000;85:587-596.

6. Clarke S. Perceptions of organizational safety: implications for the development of safety culture. J Organ Behav. 1999;20:185-198.

7. Jha AK, Prasopa-Plaizier N, Larizgoitia I, Bates DW. Research priority setting working group of the WHO world alliance for patient safety. Patient safety research: an overview of the global evidence. Qual Saf Health Care. 2010;19:42-47.

8. Jha AK, Larizgoitia I, Audera-Lopez C, Prasopa-Plaizier N, Waters H, Bates DW. The global burden of unsafe medical care: analytic modelling of observational studies. BMJ Qual Saf. 2013;22:809-815.

9. Chen I-C, Li H-H. Measuring patient safety culture in taiwan using the hospital survey on patient safety culture (HSOPSC). BMC Health Serv Res. 2010;10:152.

10. Carpenter KB, Duevel MA, Lee PW, et al. Methods \& measures working group of the WHO world alliance for patient safety. Measures of patient safety in developing and emerging countries: a review of the literature. Qual Saf Health Care. 2010;19:48-54.

11. Wilson RM, Michel P, Olsen S, et al. Patient safety in developing countries: retrospective estimation of scale and nature of harm to patients in hospital. BMJ. 2012;344:e832

12. Association of Healthcare Research and Quality. 2017; 2017. Available from: http:// www.ahrq.gov/qual/hospsurveydb/index.html.

13. Flin R. Measuring safety culture in healthcare: a case for accurate diagnosis. Saf Sci. 2007; 45:653-667

14. Colla JB, Bracken AC, Kinney LM, Weeks WB, Measuring patient safety climate: a review of surveys. Qual Saf Health Care. 2005;14:364-366.

15. Hellings J, Schrooten W, Klazinga N, Vleugels A. Challenging patient safety culture: survey results. Int J Health Care Qual Assur. 2007;20:620-632.

16. Liberati A, Altman DG, Tetzlaff J, et al. The PRISMA statement for reporting systematic reviews and meta-analyses of studies that evaluate healthcare interventions: explanation and elaboration. BMJ. 2009;339:b2700.

17. DerSimonian R, Laird N. Meta-analysis in clinical trials. Contr Clin Trials. 1986;7:177-188

18. Higgins JP, Thompson SG, Deeks JJ, Altman DG. Measuring inconsistency in metaanalyses. BMJ. 2003;327:557-560.

19. Egger M, Davey Smith G, Schneider M, Minder C. Bias in meta-analysis detected by a simple, graphical test. BMJ. 1997;315:629-634.

20. Copas J, Shi JQ. Meta-analysis, funnel plots and sensitivity analysis. Biostatistics. 2000;1:247-262

21. Abdi Z, Maleki M, Khosravi A. Staff perception about patient safety culture in selected hospitals of Tehran University of Medical Sciences. Payesh Quarterly. 2012;10:411-419.

22. Adibi H, Khalesi N, Ravaghi H, Jafari M, Jeddian AR. Development of an effective risk management system in a teaching hospital. J Diabetes Metab Disord. 2012;11:1-7

23. Agharahimi Z, Mostofi M, Jafari M, Raesi AR. Evaluation of staff attitudes about patients' safety culture in Noor \& Ali Asghar hospitals in Isfahan-2011. Hosp Q. $2012 ; 11: 17-26$.
24. Arabloo J, Rezapour A, Ebadi Fard Azar F, Mobasheri Y. Measuring patient safety culture in Iran using the hospital survey on patient safety culture (HSOPS): an exploration of survey reliability and validity. International Journal of Hospital Research 2012;1:15-28.

25. Baghaei R, Nourani D, Khalkhali H, Pirnejad H. Evaluating patient safety culture in personnel of academic hospitals in Urmia university of medical sciences in 2011. $J$ of nurs and midwife faculty of Urmia. 2012;10:155-164.

26. Ebadi fard azar F, Rezapoor A, Tanoomand Khoushehmehr A, Bayat R, Arabloo J, Rezapoor Z. Study of patients'safety culture in Selected Training hospitals affiliated whith Tehran university of medical sciences. JHOSP. 2012;11:55-64.

27. Ravaghi H, Barati Marnani A, Hosseini AF, Takbiri A. The Relationship between Health Care Providers' Perceptions of Patient Safety Culture and Patients' Perceptions of Medical Errors in Teaching Hospitals in Tehran. 2011; 2011:57-68 تاش. 2012.

28. Yaghobi Far MA, Takbiri A, Haghgoshaye E, Tabarraye Y. The survey of patien safety culture and recognizing its weknesses and strenths in sabzevar hospitals. Sabzevar Uni Med Sci J ( JSUMS). 2012;20:154-164.

29. Davoodi R, Mohammadzadeh Shabestari M, Takbiri A, et al. Patient safety culture based on medical staff attitudes in khorasan razavi hospitals, northeastern Iran. Iran $J$ Public Health. 2013;42:1292-1298.

30. Izadi AR, Drikvand J, Ebrazeh A. The patient safety culture in Fatemeh Zahra hospital of najafabad, Iran. Health Inf Manag. 2013:895-907.

31. Moghri j, Akbari Sari A, Rahimi Forooshani A, Arab M. Patient safety culture status in General hospitals affiliated to tehran university of medical sciences. Hakim Research Journal. 2013;16:243-250.

32. Moghri J, Nateghi E, Arab M, et al. Measurement of patient safety culture in Iranian hospitals: a national baseline study. J Clin Res Gov. 2013;2:47-52.

33. Moussavi F, Moghri J, Gholizadeh Y, et al. Assessment of patient safety culture among personnel in the hospitals associated with Islamic Azad University in Tehran in 2013. Electron Physician. 2013;5:664-671.

34. Bahrami MA, Chalak M, Montazeralfaraj R, Dehghani Tafti A. Iranian nurses' perception of patient safety culture. Iran Red Crescent Med J. 2014;16:e11894

35. Faghihzadeh S, Motamed N, Shoghli AR, Asuri M, Safaian Amoli M. Assessment of nurse viewpoints on patient safety culture in amol hospitals in Iran. PCNM. 2012;2014(4):45-55.

36. Momeni B, Golpira R, Mg M. The study of the domains of patient safety culture in Rajaie Cardiovascular, Medical and Research Center in 2012. Cardiovasc Nursing J. 2014:3:34-41.

37. Almasi A, Pourmirza Kalhori R, Ahmadi Jouybari T, Goodarzi A, Ahmadi AR. Evaluation of patient safety culture in personnel of hospitals in Kermanshah, 2013. J Clin Res Paramed Sci. 2015;4:14-23.

38. Arshadi Bostanabad M, Shirzad G, Motazedi Z, Asghari E, Safari A. Barriers of nurses participation in clinical research in Tabriz training centers, 1393. IJNR. 2015;10:43-51.

39. Hemmat F, Atashzadeh-Shoorideh F, Mehrabi T, Zayeri F. A survey of nurses' awareness of patient safety culture in neonatal intensive care units. Iran $J$ Nurs Midwifery Res. 2015;20:490-495.

40. Mohebi Far R, Alijan zade M, Safari Variani A, et al. Studying patient safety culture from the viewpoint of staffs in educational hospitals in Tehran City. JHSW. 2015;5:57-64

41. Saber M, Tehrani H, Hasani Kabootarkhani M, Ghorban Sabagh M, Bagheri M. Acquaintance of kerman hospitals' staff about patient safety culture. J Health Dev. 2015;4:124-132.

42. Kabodi S, Ghanbari M, Ashtarian H, Bagheri F, Ajamin E. Assessing elements of patient safety culture in Kermanshah health care and educational centers. JHSW. 2016;6:63-74

43. Rezaean M, Aqaie Borz Abad P, Yazdanpanah A, Zinat Motlagh SF. Patient safety culture status from the perspective medical staff of Yasuj hospitals in 2015 Armaghane-danesh. 2016;20:935-946.

44. Akbari N, Malek M, Ebrahimi P, Haghani H, Aazami S. Safety culture in the maternity unit of hospitals in Ilam province, Iran: a census survey using HSOPSC tool. Pan Afr Med J. 2017;27:268.

45. Asefzadeh S, Kalhor K, Tir M. Patient safety culture and job stress among nurses in Mazandaran, Iran. Electron Physician. 2017;9:6010-6016.

46. Farzi S, Moladoost A, Bahrami M, Farzi S, Etminani R. Patient safety culture in intensive care units from the perspective of nurses: a cross-sectional study. Iran $J$ Nurs Midwifery Res. 2017;22:372-376.

47. Ghahramanian A, Rezaei T, Abdullahzadeh F, Sheikhalipour Z, Dianat I. Quality of healthcare services and its relationship with patient safety culture and nurse-physician professional communication. Health Promot Perspect. 2017;7:168-174.

48. Famolaro T, Yount N, Burns W, Flashner E, Liu H. Hospital Survey on Patient Safety Culture 2016 User Comparative Database Report. (Prepared by Westat, Rockville, MD, under Contract No. HHSA 290201300003C) Rockville: Agency for Health care Research and Quality. AHRQ Publication; 2016 16-0021-EF.

49. El-Jardali F, Jaafar M, Dimassi H, Jamal D, Hamdan R. The current state of patient safety culture in Lebanese hospitals: a study at baseline. Int J Qual Health Care. 2010;22:386-395.

50. Mekonnen AB, McLachlan AJ, Brien JE, Mekonnen D, Abay Z. Hospital survey on patient safety culture in Ethiopian public hospitals: a cross-sectional study. Saf Health. 2017;3:11.

51. Güneș Ü.Y, Gürlek Ö, Sönmez M. A survey of the patient safety culture ofhospital nurses in Turkey. Collegian. 2016;23:225-232.

52. Etchegaray JM, Thomas EJ. Comparing two safety culture surveys: safety attitudes questionnaire and hospital survey on patient safety. BMJ Qual Saf. 2012;21:490-498.

53. Alahmadi HA. Assessment of patient safety culture in Saudi Arabian hospitals. Qual Saf Health Care. 2010;19:e17

54. Chen IC, Li HH. Measuring patient safety culture in taiwan using the hospital survey 
on patient safety culture (HSOPSC). BMC Health Serv Res. 2010;10:152.

55. Al-Mandhari A, Al-Zakwani I, Al-Kindi M, Tawilah J, Dorvlo ASS, Al-Adawi S. Patient safety culture assessment in Oman. Oman Med J. 2014;29:264-270.

56. Sarac C, Flin R, Mearns K, Jackson J. Hospital survey on patient safety culture: psychometric analysis on a Scottish sample. BMJ Qual Saf. 2011;20:842-848.

57. Kim J, An K, Kim MK, Yoon SH. Nurses' perception of error reporting and patient safety culture in Korea. West J Nurs Res. 2007;29:827-844.

58. Pronovost PJ, Berenholtz SM, Goeschel CA, et al. Creating high reliability in health care organizations. Health Serv Res. 2006;41:1599-1617.

59. El-Jardali F. Hospital accreditation in Lebanon: its potential for quality improvement. Leban Med J. 2007;55:39-45.

60. Yousefinezhadi T, Mosadeghrad AM, Arab M, Ramezani M, Sari AA. An analysis of hospital accreditation policy in Iran. Iran J Public Health. 2017;46:1347-1358.

61. Movahednia S, Partovishayan Z, Bastanitehrani M, Moradi F. Nurse Managers' perspectives about Reasons for not reporting medical errors in Firoozgar Hospital: 2012. RJMS. 2014;21:110-118. 